\title{
Application of Colour Asphalt Pavement Technology in Municipal Road Construction
}

\section{Zhou Liping}

Yunnan Technology and Business College, Yunnan, China

Keywords: Municipal roads; Colored asphalt; Construction; Technology.

Abstract: With the improvement of urban planning and design, color asphalt pavement can beautify the city and induce traffic, so it is more and more used in municipal road engineering. In this paper, the control factors of color asphalt construction are analyzed and sorted out.

\section{Introduction}

Coloured asphalt is a kind of road construction material with decorative function, which has been gradually rising in recent years. Pedestrians and vehicles can distinguish different functions of roads through different colours, to make road traffic more humane. The performance index of colour asphalt is shown in Table 1 below.

Table 1 The performance index of colour asphalt

\begin{tabular}{|c|c|c|c|c|c|c|}
\hline \multirow{2}{*}{ index } & \multirow{2}{*}{ Company } & \multicolumn{5}{|c|}{ Asphalt label } \\
\hline & & \multicolumn{5}{|c|}{ Number 70} \\
\hline Penetration $25^{\circ} \mathrm{C}, 100 \mathrm{~g}, 5 \mathrm{~s}$ & $0.1 \mathrm{~mm}$ & \multicolumn{5}{|c|}{$60 \sim 80$} \\
\hline Applicable climatic zoning & & $1-3$ & $1-4$ & $2-2$ & $2-3$ & $2-4$ \\
\hline Ductility $15^{\circ} \mathrm{C}, 5 \mathrm{~cm} / \mathrm{min}$, Not less than & $\mathrm{cm}$ & \multicolumn{5}{|c|}{100} \\
\hline softening point, Not less than & ${ }^{\circ} \mathrm{C}$ & \multicolumn{2}{|c|}{46} & \multicolumn{3}{|c|}{45} \\
\hline $\begin{array}{c}\text { The dynamic viscosity is not greater than } \\
\text { or equal to }\left(60^{\circ} \mathrm{C}\right)\end{array}$ & Pa.s & \multicolumn{5}{|c|}{160} \\
\hline The solubility is not less than or equal to & $\%$ & \multicolumn{5}{|c|}{99.5} \\
\hline \multicolumn{7}{|c|}{ Residues after TFOT (or RTFOT) } \\
\hline The change in quality is not greater than & $\%$ & \multicolumn{5}{|c|}{ \pm 0.8} \\
\hline Penetration $25^{\circ} \mathrm{C}$, Not less than & $\%$ & \multicolumn{5}{|c|}{61} \\
\hline Ductility $15^{\circ} \mathrm{C}$, Not less than & $\mathrm{cm}$ & \multicolumn{5}{|c|}{15} \\
\hline
\end{tabular}

\section{Material requirements}

Firstly, the binder used in the colour asphalt mixture is the binder component of the colour asphalt mixture, which plays a decisive role in the performance of the mixture. The main indexes of the binder used in the colour asphalt mixture should meet the A-level standard of the road petroleum asphalt stipulated in the Technical Specification for Construction of Highway Asphalt Pavement (JTG F40-2004) ${ }^{[1]}$.

Secondly, the colouring component in the colour asphalt mixture replaces part of the mineral powder in the mixing process and adds the mineral powder into the mixture at the same time. Therefore, the special colorant for colour asphalt pavement should not only have lasting and stable colour, uniform dispersion in the mixture, but also have the basic properties of mineral powder. Special colorants for colour asphalt pavement should not fade under long-term ultraviolet irradiate have excelling, insoluble in water and general solvents, easy to disperse in binders, indent weather resistance.

Thirdly, in order to ensure the durability of asphalt pavement and improve the brightness of the pavement, it is suggested that a layer of asphalt protective layer should be added to the asphalt 
pavement which has been constructed in time. Because the covered asphalt protective layer has protective effect on the asphalt pavement, the colour of the colour asphalt mixture on the bottom is comparatively close ${ }^{[2]}$, and it has significant effect on the colour effect.

Fourthly, acrylic fibre reinforced with high strength and peanut-like cross-section is added to the colour asphalt mixture, and the dosage is $0.3 \%$ of the total amount of asphalt mixture. Acrylic fibre is a kind of organic synthetic fibre, which has the characteristics of high strength, insolubility, strong adsorb ability, non-expansion in solvents and stable chemical properties. It is not only a stabilizing additive, but also can improve the structure of asphalt colloid and play the role of reinforcing bars.

Fifthly, the temperature resistance of acrylic fibres can reach 200 without changing to meet different mixing temperatures; the reinforcement of acrylic fibres improves the shear strength of asphalt mixtures at high temperatures; the rutting of pavement can be reduced by $35 \%-60 \%$ when acrylic fibres are added to asphalt mixtures after a long-term field observation for a year; and the asphalt concrete can be improved by acrylic fibres. Low temperature brittleness can improve the flexibility of pavement and reduce pavement cracking.

Sixthly, rough aggregate should be rolled or artificial colour gravel with clean surface, dry, weather less, no impurities, rich edges and corners, hard texture, cuboid particles and few needles and flakes. Its colour should be like that of pavement ${ }^{[3]}$.

Seventh, fine aggregates are usually made of natural sand or artificial sand and can be replaced by stone chips in areas where sand is scarce. Fine aggregates should be clean, dry, weather less, impurity-free, with appropriate particle size distribution, and have good bonding strength with cementing materials. The cleanliness of fine aggregates is expressed by the percentage of natural sand less than $0.075 \mathrm{~mm}$, and that of stone chips and machine-made sand by sand equivalent (0-4.75 mm) or methylene blue $(0-2.36 \mathrm{~mm}$ or $0-0.15 \mathrm{~mm})$.

Eighth, hot mixing and hot paving colour pavement colorant is used as part of the filler, and the inadequate part of the filler should be made of alkaline strong basic rock (hydrophobic stone) ground to obtain mineral powder. When acidic stone, sand or stone chips are used as fillers, appropriate anti-stripping agents should be added to improve the adhesion between mineral materials and cementing materials. All fillers should be clean, dry and have good adhesion with cementing materials.

\section{Construction requirements}

\subsection{Decrease in Color}

The main difference between colour asphalt binder and traditional black asphalt is to reduce its colour degree based on guaranteeing various properties of asphalt. At present, there is no professional mixing equipment in the construction of colour asphalt. It is necessary to use black asphalt mixing plant to mix colour asphalt mixture after simple modification of some equipment involved in colour asphalt binder ${ }^{[4]}$. The main equipment to be reformed are asphalt tank, pipeline and asphalt pump.

\subsubsection{Asphalt tank}

According to the actual situation of the project, an asphalt tank can be added if conditions permit; a simple asphalt pool can be made if conditions are not met, and the metering pipeline can be directly connected to the mixing cylinder by pipeline.

\subsubsection{Pipeline}

Because of the accumulation of black asphalt residue in the black asphalt pipeline, it is impossible to clean it, so a new pipeline with heating pipeline is needed to prevent the pipeline from being blocked by colour cementing material. The upper end of the pipeline is directly connected to the original black asphalt metering pump. The original metering pump can be cleaned with hot diesel oil. Generally, after 2 to 3 times of scouring, the interior is basically clean ${ }^{[5]}$. 


\subsubsection{Asphalt Pump}

It is necessary to add an asphalt pump to the pipeline to ensure that the cementing material can meet the normal operation of the equipment. According to the actual situation of the mixing plant, the model of the asphalt pump is determined.

\subsubsection{Other parts}

The asphalt mixing cylinder needs to be cleaned with hot aggregate to clean the black asphalt residue in the mixing cylinder.

\subsection{Method of mixing color asphalt mixture with ordinary asphalt mixture}

The mixing temperature of colour asphalt mixture should not be too high. Generally, the highest temperature should be controlled at $180 \mathrm{C}$, the temperature of cementing material can be controlled at 160-180 C, the temperature of stone should not be higher than $200 \mathrm{C}$, and the temperature of mixture should generally be controlled in the range of $160+10 \mathrm{C}$. The actual temperature should be determined according to the distance between mixing plant and site and the weather condition of construction. Truck hoppers for transporting coloured asphalt mixtures should be cleaned beforehand to minimize pollution and insulated with canvas cloth. At the same time, mixing speed and transportation speed should be well controlled according to paving capacity.

\subsection{Clean colored asphalt before paving and spray emulsified asphalt or hot asphalt viscose oil}

Whether mechanical or manual paving, all equipment and tools must be cleaned and kept clean during construction. The mixture must be paved before $130 \mathrm{C}$ and rolled at $130 \mathrm{C}$. Rolling is carried out according to the standard rolling method of black asphalt. Rollers should not be too large. It is suggested that roller under $12 \mathrm{t}$ be used for rolling. After the completion of the road surface, pay attention to maintenance, must ensure that the maintenance time is not less than 6 hours.

\subsection{Clean construction pollutants in time}

During the construction process, the pollutants brought by construction machinery must be cleaned up immediately, especially oil pollution, and must be washed with clean water immediately. Artificial construction can be used for small area, inconvenient mechanical construction, and colour asphalt pavement or other landscape pavement with low strength requirements, such as pavement or the passageway of parks and squares. Artificial paving should be operated by skilled workers to ensure smooth pavement.

\subsection{Construction Requirements of Polyacrylonitrile AS Fiber}

The action mechanism of polyacrylonitrile AS fibre in asphalt mixture mainly includes adsorption, dispersion, stabilization, reinforcing and toughening. It improves the high temperature rutting performance and low temperature cracking performance of asphalt mixture. Firstly, PAN AS fibres are packed quantitatively, mixing time and packaging need not be removed. Material and packaging materials can be put into the observation holes of mixing plant together. In addition, dry mixing time can be prolonged to ensure that the dispersion of fibres in asphalt mixtures is uniform enough. Secondly, PAN AS fibres are packaged quantitatively and need to be manually moved to the mixing plant platform. When aggregate and fibre enter the mixing cylinder, dry mixing should be carried out first. The time of dry mixing should be controlled by a delay device, which is generally set at $10 \mathrm{~s}$ to $15 \mathrm{~s}$, including the time required for manual feeding. After dry mixing, asphalt oil is added for wet mixing. The mixing time is not less than 30 seconds. The principle is to mix evenly. After adding PAN AS fibre, the speed of paver should be controlled. Because adding PAN AS fibre, the cohesion of asphalt mixture increases, the fluidity decreases, and the speed of paver should be slowed down relatively. Otherwise, the compactness of formed surface is poor. In addition, because of its high cohesion, it is not conducive to manual scraping and spreading. Thirdly, the quality control of PAN AS fibre asphalt concrete must pay attention to the dispersion of fibres at any time besides the control of ordinary asphalt concrete. It is not allowed for fibres to form aggregate blocks. If it is found that fibres form aggregate blocks, the mixing time should be 
readjusted.

\subsection{Construction Requirements of Rolling Compaction}

Rolling is an important link to ensure that the physical and mechanical properties and functional characteristics of asphalt concrete meet the design requirements and is also the last important process of asphalt surface construction. The rolling of asphalt concrete surface is usually divided into three stages: initial compression, repression and final compression. The first stage of initial pressure is also known as the stabilization stage. Because the asphalt mixture has been preliminarily compacted and compacted before ironing by paver, and the temperature of the mixture just paved is not less than $160 \mathrm{C}$, so the compaction effect can be achieved and stabilized with a smaller compaction function. The BM203AD/4 double-wheel vibratory roller imported from Germany is planned to be rolled 2-3 times at a speed of about $2 \mathrm{~km} / \mathrm{h}$. During the rolling, the driving wheel advances at a uniform front static pressure speed, and when it recedes, it runs along the track of the forward rolling wheel and vibrates. The second stage of re-compaction is the main stage of compaction. At least the required degree of compaction should be achieved at this stage. Therefore, the re-compaction should be carried out at a higher temperature and immediately after the initial compaction. The temperature during repression should not be lower than $150 \mathrm{C}$, and the rolling method is the same as the initial pressure. The third stage of final pressure is the last step to eliminate defects and ensure surface smoothness. Because final pressure is to eliminate surface irregularities left over during repression, asphalt mixture also needs higher temperature. Static double-wheel roller is usually used for final pressure, which is immediately followed by re-pressing. The temperature at the end of final pressure should not be lower than $90^{\circ} \mathrm{C}$ stipulated in the construction code of asphalt pavement, and the final pressure should be ended at a higher temperature as far as possible.

\section{Conclusion}

In summary, the application of colour asphalt pavement in municipal road engineering is increasing, and its importance is also increasing. In this paper, the control factors of colour asphalt construction are analysed and sorted out, hoping to bring some inspiration to the follow-up research and practice.

\section{References}

[1] Huang Fang. Discussion on the application of new materials in municipal road construction [J]. Juye, 2018 (01): 134-135.

[2] Cui Yong, Chen Junsheng, Fan Liang. Production and Control of Colored Asphalt Concrete in Municipal Pavement [J]. Shanxi Architecture, 2015, 41 (23): 104-105.

[3] Chen Chengqin. Research on pavement performance of color asphalt and its mixture [D]. Chang'an University, 2012.

[4] Li Zengmin. Construction technology control of colour asphalt concrete pavement in municipal roads [J]. Traffic standardization, 2010 (Z1): 189-191.

[5] Hong Society. Application of colour asphalt concrete in municipal roads [J]. Science and technology information, 2010 (05): $675+647$. 